\title{
Safety In Service Operations: A Frontline Perspective
}

\author{
Joanne S. Utley, North Carolina A\&T State University, USA \\ Rhonda L. Hensley, North Carolina A\&T State University, USA \\ Kathryn Dobie, North Carolina A\&T State University, USA
}

\begin{abstract}
This paper identifies service safety as separate dimension of quality and considers the need to view safety from the frontline worker's perspective. Stewart's (2003) "3 T" framework is used to categorize safety training elements by task, treatment and tangibles. Results from a survey of public transit bus drivers are presented. Results show that the questions categorized as treatment and tangibles were significant predictors of perceived safety.
\end{abstract}

Keywords: service safety, frontline workers and systems framework

\section{INTRODUCTION}

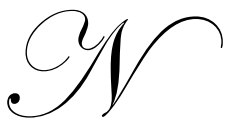

o one wants to patronize a service that may pose safety risks to its customers. All frontline service employees understand this notion intuitively and many realize that they play a major role in ensuring a safe service environment. Frontline employees also know, perhaps better than anyone in the service organization, how well the service is achieving its safety goals. Their first hand experience with customer safety offers insights that external audits and managerial oversight cannot provide.

The service management literature has long emphasized the importance of the frontline employee in maintaining service quality (Chase and Stewart, 1994; Stewart and Chase, 1999; Chase, 1978; Chase and Bowen, 1991). However, past research has seldom considered safety as a separate dimension of service quality; instead, other components such as timeliness, completeness, courtesy, consistency, accessibility, accuracy and responsiveness are commonly delineated as key service quality dimensions (Evans and Lindsay, 1996). In contrast, safety has always been a key dimension of product quality (Garvin, 1984). This study will follow the approach to safety taken in the manufacturing literature and identify service safety as a separate dimension of quality. Such an approach intensifies the need to view safety from the frontline worker's perspective. This study will describe a survey methodology designed to gain this frontline perspective and will report the results of its implementation in an actual service context.

This paper is organized as follows. The following section will present a framework for classifying various components of customer safety in a service setting. A discussion of the research context and methodology follows the framework description. Next, the results from the methodology implementation are given. The paper concludes with the managerial implications of the study and suggestions for further research.

\section{SERVICE SAFETY FRAMEWORK}

Like service quality, service safety involves a wide array of individual service attributes. The size of the attribute set will vary with the particular service context. Even though the size of the attribute set may vary, a systems based framework can help the manager organize the attributes by major system component type. A number of such frameworks have been described in the service quality literature (See, for instance: (Stewart, 2003; Chase and Bowen, 1991; Shostack, 1987 and Heskett, 1987). The number of components in these frameworks is limited; usually only three components comprise the framework. As Stewart (2003, p.248) has observed, the framework components "provide a perspective that is closely aligned to the actual decision making and manipulation of the 
operations manager." Stewart's rationale for collapsing multiple attributes into a small set of major service components applies to service safety. Consequently, this paper will adopt the systems framework proposed by Stewart (2003) and use it to classify a range of service elements related to safety.

Stewart's (2003) framework consists of three major components. These are: 1) task, 2) treatment and 3) tangibles. In the service literature, these three components are collectively known as the " 3 T's." According to Stewart (2003, p.448), the task component can be defined as "what must be done." Task obviously includes the core service activity. For example, in a public bus system, the core task is transit. In the restaurant industry, the core task is food preparation. In addition to the core task, the task component encompasses processes, procedures and algorithms. In describing the task component of the " 3 T's" model, Stewart (2003, p. 249), delineates the following characteristics of a task: 1) it is "temporal in nature" because every task has a specific start time and a specific finish time, 2) a task may be planned in advance but often depends on the resolution of the actual service encounter for its completion, 3) task evaluation can include both time-based measures and more subjective elements.

In contrast to the task component, the treatment component deals primarily with the "emotional/social context of the encounter" (Stewart, 2003, p.248). Thus, the treatment component encompasses interactions that occur between the service worker and the customer. The role of frontline service workers in these interactions can not be under-estimated since "service employees represent the organization in the customers' eyes and in many instances they are the service" (Cook, Bowen, Chase, Dasu, Stewart and Tansik, 2002, p. 167). For example, a rude waiter can spoil an otherwise pleasant dining experience for a customer and leave that customer with a negative impression of the particular restaurant. On the other hand, an empathetic flight attendant can reassure an anxious airplane passenger and thus help the passenger enjoy flying on that particular airline.

Finally, the tangibles component differs from the preceding two components in that it refers to the "facilities and the facilitating goods of the service" (Stewart, p. 248). Stewart (2003) underscores the following characteristics of the tangibles component: 1) it is relatively easy to measure performance in the tangibles category and evaluation criteria are typically objective and easy to understand, 2) tangibles encompass such issues as functionality, maintenance and repair and 3) much of the work in managing tangibles can be performed without any customer involvement. For instance, in a public transit system vehicle maintenance is routinely scheduled, performance is easily measured by metrics like fuel mileage, tire wear and brake lining wear and maintenance activities occur in a work area that is not accessible to riders.

While the " 3 T's" help the service manager to integrate a variety of service attributes into a single framework, they cannot by themselves render a complete view of service safety at an individual service operation. However, when used in conjunction with the first hand knowledge that frontline workers possess, the " 3 T" framework can help the service manager determine which service elements to emphasize to promote service safety. The following section describes such an application of the " $3 \mathrm{~T}$ 's" framework in an actual service setting.

\section{METHODOLOGY AND CONTEXT}

\section{Context}

The research context for this study was an urban transit system located in western North Carolina. The system has been in operation for over 19 years and logged over three million passenger trips in 2009. The buses operate seven days a week and cover 15 routes. While the transit system provides service on regular city routes, furnishes paratransit services and operates a university-based system, the bus drivers for the regular city routes were the only frontline workers who participated in this study.

\section{Methodology Application}

Working in conjunction with the transit director and the director of safety, the authors devised a survey to assess bus drivers' perceptions of service safety at this transit operation. Table 1 lists the nine safety-related attributes that were used as survey items. In completing these questions, the drivers had to assess the degree to which the system has emphasized each item during training. All nine questions were measured on a Likert-scale 
ranging from one which was defined as no emphasis in training, to five which was defined as much emphasis in training. Training encompassed not only the formal training sessions all new drivers must attend but also safety assurance programs, workshops and monthly drivers' meetings.

As Table 1 shows, the survey contained a tenth item which asked the drivers to rate the overall level of safety at this transit system. To answer this question, the drivers reflected on their entire experience at this system, not solely on their training experience. Question 10 used a Likert scale which ranged from 1, which designated very low levels of driver perceived safety, to 5 , which corresponded to very high levels. The bus driver surveys were completed at a regular monthly drivers' meeting and were administered by the safety director. All surveys were anonymous. A total of 87 surveys were collected at the end of the meeting. A total of 73 were complete.

Table $1^{1}$

Means, Standard Deviations And Correlations

\begin{tabular}{|c|c|c|c|c|c|c|c|c|c|c|c|c|}
\hline \multirow[b]{2}{*}{ Question } & \multirow[b]{2}{*}{ Mean } & \multirow{2}{*}{$\begin{array}{l}\text { Standard } \\
\text { Deviation }\end{array}$} & \multicolumn{10}{|c|}{ Correlations } \\
\hline & & & 1 & 2 & 3 & 4 & 5 & 6 & 7 & 8 & 9 & 10 \\
\hline $\begin{array}{l}\text { 1. Emphasis on Policies } \\
\text { and Procedures }\end{array}$ & 3.96 & 1.123 & - & .506 & .548 & .677 & .410 & .640 & .554 & .529 & .452 & .529 \\
\hline $\begin{array}{l}\text { 2. Emphasis on } \\
\text { Equipment Operation }\end{array}$ & 4.05 & 1.079 & & - & .443 & .622 & .357 & .468 & .472 & .476 & .421 & .620 \\
\hline 3. Emphasis on Security & 3.82 & 1.183 & & & - & .463 & .460 & .464 & .532 & .394 & .565 & .425 \\
\hline $\begin{array}{l}\text { 4. Emphasis on } \\
\text { Passenger Safety }\end{array}$ & 4.36 & 1.005 & & & & - & & .682 & .573 & .648 & .455 & .545 \\
\hline $\begin{array}{l}\text { 5. Emphasis on Rider } \\
\text { Relations }\end{array}$ & 3.90 & 1.169 & & & & & - & .609 & .694 & .593 & .508 & .445 \\
\hline $\begin{array}{l}\text { 6. Emphasis on Incident } \\
\text { Recognition }\end{array}$ & 4.10 & 1.145 & & & & & & - & .627 & .632 & .473 & .497 \\
\hline $\begin{array}{l}\text { 7. Emphasis on Incident } \\
\text { Handling }\end{array}$ & 4.25 & 0.954 & & & & & & & - & .836 & .524 & .525 \\
\hline $\begin{array}{l}\text { 8. Emphasis on Incident } \\
\text { Reporting }\end{array}$ & 4.19 & 1.089 & & & & & & & & - & .359 & .378 \\
\hline $\begin{array}{l}\text { 9. Emphasis on Practice } \\
\text { Driving with Experienced } \\
\text { Driver }\end{array}$ & 3.99 & 1.286 & & & & & & & & & - & .474 \\
\hline $\begin{array}{l}\text { 10. How Would You } \\
\text { Rate the Level of Safety? }\end{array}$ & 3.97 & .957 & & & & & & & & & & - \\
\hline
\end{tabular}

${ }^{1} \mathrm{n}=73$ and all correlations significant at $\mathrm{p} \leq .001$

The descriptive statistics that resulted from the preliminary data analysis of the survey data are shown in Table 1. These results reveal that the drivers perceived the greatest system emphasis on passenger safety (mean $=$ 4.36) and incident handling $($ mean $=4.25)$. In contrast, Table 1 reveals that drivers perceived the least emphasis on security (mean $=3.82)$ and rider relations $($ mean $=3.90)$.

Table 2 presents the next stage in the preliminary analysis in which the " $3 \mathrm{~T}$ 's" framework was used to collapse the first 9 survey items into three broad categories. As Table 2 shows, items dealing with policies and procedures, incident reporting and practice driving were put in the task category. Collectively, these items reflect the core task (driving) and also processes (policies and procedures and incident reporting). The treatment category contains items relating to security, passenger safety, rider relations, incident recognition and incident handling. These items deal with interactions occurring between the driver and the bus passengers. The final category, tangibles, contained only the item corresponding to equipment operation. This category reflects such issues as functionality and maintenance, which are two important considerations in safe equipment operation. The descriptive statistics for the " $3 \mathrm{~T}$ 's" shown in Table 3 reveal that the means for all three categories were similar (task mean= 4.0456 , treatment mean $=4.0849$ and tangibles mean $=4.0548$ ). Table 3 also shows that treatment and task were positively correlated. 
Table 2

Stewart's “3t" Framework

\begin{tabular}{|l|l|}
\hline \multicolumn{1}{|c|}{ Framework Category } & \multicolumn{1}{c|}{ Survey Question } \\
\hline \multirow{3}{*}{ Task } & 1. Emphasis on Policies and Procedures \\
& 8. Emphasis on Incident Reporting \\
& 9. Emphasis on Practice Driving with Experienced Driver \\
\hline \multirow{3}{*}{ Treatment } & 3. Emphasis on Security \\
& 4. Emphasis on Passenger Safety \\
& 5. Emphasis on Rider Relations \\
& 6. Emphasis on Incident Recognition \\
& 7. Emphasis on Incident Handling \\
\hline Tangibles & 2. Emphasis on Equipment Operation \\
\hline
\end{tabular}

Table $3^{1}$

Means, Standard Deviations And Correlations For The “3t” Framework

\begin{tabular}{|l|c|c|c|c|c|}
\hline \multicolumn{1}{|c|}{ Category } & Mean & $\begin{array}{c}\text { Standard } \\
\text { Deviation }\end{array}$ & Task & Treatment & Tangibles \\
\hline Task & 4.0456 & 0.92524 & - & .878 & .587 \\
\hline Treatment & 4.0849 & 0.87173 & & - & .586 \\
\hline Tangibles & 4.0548 & 1.07871 & & & - \\
\hline
\end{tabular}

${ }^{1} \mathrm{n}=73$ and all correlations significant at $\mathrm{p} \leq .0001$

Since the " 3 T's" framework can help guide decision making in a service operation, it is useful to consider how the task, treatment and tangibles categories delineated in Table 3 affect the bus drivers' perceived transit safety at this transit operation. To examine this question, the authors used regression analysis to model the relationship between perceived safety and the " 3 T's." The results of this analysis are given in the next section. In addition, the results of a second model in which perceived safety is modeled as a function of the nine individual safety items are also presented.

\section{RESULTS}

In the initial regression model, the dependent variable, the perceived level of safety (Question 10), was regressed against the average scores for task, treatment and tangibles. Stepwise regression resulted in a model which included tangibles and treatment as independent variables but omitted task (see Table 4). The model had an adjusted $\mathrm{R}^{2}$ of $45.9 \%$ and was significant at $\mathrm{p}$-value <.0001. Individual t-tests showed that both variables were significant in the final model (tangibles had a p-value of <.0001 and treatment had a p-value of .001). The variance inflation factor was 1.522, well below the accepted limit of ten (Hair, Black, Babin, Anserson and Tatham, 2005; Cohen, Cohen, West and Aiken, 2003; Neter, Wasserman and Kutner, 1985) (See Table 5). The regression equation may be stated

$\mathrm{Y}=.963+.359 X_{\text {Tangibles }}+.405 X_{\text {Treatment }}$

Table $4^{1}$

Regression Results For The "3t" Model

Dependent Variable: Overall Level Of Safety

\begin{tabular}{|c|c|c|}
\hline Predictor & Beta & P-Value for T Test \\
\hline Treatment & .405 & .001 \\
\hline Tangibles & .359 & $<.0001$ \\
\hline
\end{tabular}

${ }^{1} \mathrm{n}=73$; Adjusted $\mathrm{R}^{2}=45.9 \%$; Model Significant at $\mathrm{p} \leq .0001$ 
Table $5^{1}$

Multicollinearity Measures For The "3t" Model

\begin{tabular}{|c|c|c|}
\hline Variable & Tolerance & Variance Inflation Factor \\
\hline Treatment & .657 & 1.522 \\
\hline Tangibles & .657 & 1.522 \\
\hline
\end{tabular}

In the second model, the dependent variable, perceived level of safety, was regressed against the nine attributes (found in items 1-9) using Stepwise regression. The analysis identified a four-variable model consisting of: $X_{2}$ (training emphasis on equipment operation), $X_{7}$ (emphasis on incident handling), $X_{8}$ (emphasis on incident reporting) and $X_{4}$ (training emphasis on passenger safety) (see Table 6). The model had an adjusted $\mathrm{R}^{2}$ of $49.1 \%$ and was significant ( $\mathrm{p}$-value <.001). Individual t-tests showed that all the variables were significant in the model ( $\mathrm{p}$ values ranged from .0001 to .038). Multicollinearity was not considered a problem because the variance inflation factors ranged from a low of 1.687 to a high of 3.870 (Hair, Black, Babin, Anserson and Tatham, 2005; Cohen, Cohen, West andAiken, 2003; Neter, Wasserman and Kutner, 1985) (Table 7). The resulting regression equation may be stated as

$\mathrm{Y}=.689+.362 X_{2}+.565 X_{7}-.403 X_{8}+.252 X_{4}$

\section{DISCUSSION}

The regression results presented in the preceding section yielded several managerial implications for the transit system in this study. These deal with the relative importance of task, treatment and tangibles, the apparent lack of significance of certain survey items and the role of worker training in service safety.

The results of the first regression analysis revealed that the task category was not a significant predictor of perceived safety. This result is not surprising given the three items that comprise this category: 1) policies and procedures, 2) incident reporting and 3) practice driving. Emphasis placed on these items during training does not translate into higher perceived safety. For instance, practice driving with an experienced driver is less relevant for an experienced bus driver who most likely increases his driving skill every day just by doing his job. In the second regression model, the negative beta coefficient for emphasis on incident reporting indicates an inverse relationship between incident reporting and perceived passenger safety. In this case, drivers equate more emphasis on reporting with "more red tape" and less time available for the really important safety issues.

Table $6^{1}$

Regression Model For The Safety Attributes Dependent Variable: Overall Level Of Safety

\begin{tabular}{|l|c|c|}
\hline \multicolumn{1}{|c|}{ Predictor } & Beta & P-Value for T Test \\
\hline 2. Training emphasis on equipment operation & .362 & .0001 \\
\hline 7. Training emphasis on incident handling & .565 & .001 \\
\hline 8. Training emphasis on incident reporting & -.403 & .007 \\
\hline 4. Training emphasis on passenger safety & .252 & .038 \\
\hline
\end{tabular}

${ }^{1} \mathrm{n}=73$; Adjusted $\mathrm{R}^{2}=49.1 \%$; Model Significant at $\mathrm{p} \leq .001$

Table $7^{1}$

Multicollinearity Measures For The Attribute Model

\begin{tabular}{|l|c|c|}
\hline \multicolumn{1}{|c|}{ Variable } & Tolerance & Variance Inflation Factor \\
\hline 2. Training emphasis on equipment operation & .593 & 1.687 \\
\hline 7. Training emphasis on incident handling & .293 & 3.408 \\
\hline 8. Training emphasis on incident reporting & .258 & 3.870 \\
\hline 4. Training emphasis on passenger safety & .453 & 2.207 \\
\hline
\end{tabular}


In contrast to the task category, the treatment and tangibles categories were significant variables in the first regression. Emphasis on two key items in the treatment category - handling an incident and passenger safety underscores the interactive nature of the driver's role in safety assurance. Drivers must be alert to passenger behavior to prevent mishaps or incidents from occurring and must react in an effective yet reassuring manner when incidents do occur.

Emphasis on equipment operation (tangibles) also affected drivers' perceptions of safety in this study. This result is also not surprising. Reliable equipment operation requires that a driver inspect his vehicle prior to beginning his route and make sure that routine maintenance occurs. Experienced drivers realize that such behaviors are worth emphasizing in training since they are an integral part of everyday operations.

In contrast with individual items such as equipment operation and incident handling, security was not a significant variable in the second regression. This result is rather surprising since security by definition involves denying public access to work areas or equipment in order to prevent possible incidents and accidents. Perhaps the drivers surveyed perceived security as more of a managerial issue than a front line worker issue.

This paper focused on the role of front line service workers in assuring service safety. However, just as in the broader case of service quality, the service customer can also play a more active role. This would require increased customer awareness of safety issues. In this sense, helping the customer to do a better job in his or her role as customer could help to improve service safety. Thus, the failsafing mechanisms described by Chase and Stewart (1994) could help the customer more safely navigate the service environment. The effectiveness of such mechanisms used in combination with frontline worker perspectives would provide an interesting avenue for future research.

\section{AUTHOR INFORMATION}

Dr. Utley is a Professor in the School of Business and Economics at North Carolina A\&T State University where she teaches Operations Management and Management Science. She earned the Ph.D. in Business Administration from the University of North Carolina at Chapel Hill in 1989. Dr. Utley has published in a number of refereed journals including: Operations Management Research, Journal of Operations Management, Management Science, Computers and Operations Research, Decision Sciences, International Journal of Quality and Reliability Management, International Journal of Production Economics and others. She currently serves as an Area Editor for the journal Operations Management Research.

Dr. Hensley is an Associate Professor in the School of Business and Economics at North Carolina A\&T State University. She teaches Management Science, Operations Management and Statistics. She earned the PhD in business at Virginia Commonwealth University in 1994. Dr. Hensley has published in the Journal of Transportation Management, Journal of the Transportation Research Forum, International Journal of Quality and Reliability Management, Journal of Operations Management, the International Journal of Production and Operations Management, Managing Service Quality and other publications. She is on the editorial review board for the Journal of Operations Management.

Dr. Dobie received her doctorate from the University of Memphis in 1992. She joined the faculty North Carolina A\&T State University in 1999. She serves as the Director of the Transportation Institute, Professor of Transportation and Logistics and UPS Research Chair in the School of Business and Economics. Dr. Dobie's research interests include supply chain security, service quality and the impact of internal and external relationships on logistics operations and financial performance. 


\section{REFERENCES}

1. Chase, R. B. (1978) Where does the customer fit in a service operation? Harvard Business Review, 56, 137142 .

2. Chase, R.B. \& Bowen, D. (1991) Service quality and the service delivery system: a diagnostic framework, in Service Quality: Multidisciplianry and Multinational Perspectives, S. Brown, B. Edvardsson, and B. Gustavsson, eds. Lexington, MA: Lexington Books.

3. $\quad$ Chase, R.B. \& Stewart, D.M. (1994) Make your service fail safe, Sloan Management Review, 35(3), 137142.

4. Cohen, J., Cohen, P., West, S.G. \& Aiken, L.S. (2003) Applied Multiple Regression/Correlation Analysis for the Behavior Sciences, Mahwah, NJ: Erlbaum.

5. $\quad$ Cook, L.S., Bowen, D.E., Chase, R.B., Dasu, S., Stewart, D.M. \& Tansik, D.A. (2002) Human issues in service design, Journal of Operations Management, 20, 159-174.

6. Evans, J.R. \& Lindsay, W.M. (1996) The Management and Control of Quality, $3^{\text {rd }}$ Edition, St. Paul, MN: West.

7. Garvin, D.A. (1984) What does quality really mean? Sloan Management Review, 26(1), 25-43.

8. Hair, J.F., Black, W.C., Babin, B.J., Anderson, R.E. \& Tatham, R.L. (2005) Multivariate Data Analysis, $6^{\text {th }}$ Edition, Englewood Cliffs, NJ: Pearson/Prentice-Hall.

9. $\quad$ Heskett, J.L. (1987) Lessons in the service sector, Harvard Business Review, 65(2), 118-126.

10. Neter, J., Wasserman, W. \& Kutner, M.H. (1985) Applied Linear Statistical Models, $2^{\text {nd }}$ Edition, Homewood, IL: Irwin.

11. Shostack, G.L. (1987) Service positioning through structural change, Journal of Marketing, 51(1), 34-43.

12. Stewart, D.M. (2003) Piecing together service quality: a framework for robust service, Production and Operations Management, 12(2), 246-265.

13. Stewart, D.M. \& Chase, R.B. (1999) The impact of human error on delivering service quality", Production and Operations Management, 8(3), 240-263. 


\section{NOTES}

